\title{
La imagen externa de la poesía costarricense a través de la traducción ${ }^{1}$
}

\section{(The Image Abroad of Costa Rican Poetry in Translation)}

\author{
Francisco Javier Vargas Gómez ${ }^{2}$
}

Universidad Nacional, Costa Rica

\begin{abstract}
resumen
Se estudia la traducción de literaturas periféricas a través de la poesía costarricense con dos propósitos: mostrar cómo la traducción puede configurar la imagen externa de una producción literaria nacional y describir la imagen que las traducciones le habrían conferido a la poesía costarricense en el exterior. Tras describir el panorama histórico-poético de la poesía costarricense, se presentan las correspondientes publicaciones para finalmente delinear la imagen que habría adoptado en el exterior. El resultado: las traducciones no reflejan el desarrollo histórico-poético de la lírica costarricense. Así, la traducción de literaturas periféricas resulta ser una actividad altamente condicionada, parcializada y selectiva.
\end{abstract}

\section{abstract}

The article approaches the translation of minority literatures through the case of Costa Rican poetry with two purposes: to show how translation may model the external image of a given national literature and to describe the image Costa Rican poetry has been given through its translations. Costa

1 Recibido: 12 de enero de 2014; aceptado: 5 de julio de 2014. Una versión anterior de este artículo fue presentado en la conferencia dictada en el marco de la Celebración del 40 aniversario de la Escuela de Literatura y Ciencias del Lenguaje, el día 19 de noviembre de 2013, en el Edificio de la Facultad de Filosofía y Letras de la Universidad Nacional de Costa Rica.

2 Escuela de Literatura y Ciencias del Lenguaje. Correo electrónico: vargasgomezfrancisco@ gmail.com 
Rican poetic development is summarized and the different publications in which translations of Costa Rican literature were found are reviewed, to finally describe the image imposed on Costa Rican poetry abroad. The results: The translations studied do not portray the true development of Costa Rican poetry. The translation of minority literatures is then a highly conditioned, biased, compliant and selective activity.

Palabras clave: traducción, literaturas periféricas, poesía costarricense Keywords: translation, minority literatures, Costa Rican poetry

\section{Introducción}

Hace poco más de cinco años visité elInstituto Ibero-Americano en Berlín, en compañía del profesor Miguel Ángel Vega Cernuda, de la Universidad de Alicante, estudioso de la traducción y autor de numerosas publicaciones en el campo. Nos encontrábamos en aquel lugar, porque desde hacía dos años Vega Cernuda estudiaba la traducción de la literatura costarricense y buscaba en aquella ocasión cualquier tomo original de nuestra producción literaria que hubiese llegado a Alemania.

Ya en la biblioteca mi guía se percató, con sorpresa y desaliento, que había solamente un único representante de la literatura costarricense en aquel lugar o más bien sobre literatura costarricense, ya que se trataba de un compendio bibliográfico en el que se recogía un conjunto de referencias a algunas de las publicaciones en la materia. "iQué vergüenza!», expresó. Como único representante de quienes nacimos en este país, cargué con aquella vergüenza en solitario. Sin embargo, parece que la situación ha cambiado: de las 118 referencias que aparecen a la fecha en el catálogo del Instituto Ibero-Americano en las categorías «Costa Rica» y «literatura», alrededor de un $30 \%$ remiten a obras literarias propiamente dichas. Claro que aquella cifra todavía no alcanza a ser representativa de la literatura del país. 
A partir de tal experiencia se creería que no se conocía la literatura de Costa Rica en Alemania; o bien, lo que se conocía era poco, y posiblemente menos representativo aún. Esto, claro, para no referirnos a la poesía. Si a esto añadimos el que serían relativamente pocos los alemanes, enestecaso, que habrían podido leer en español, tal parecería que nuestros escritores no contaban con un rostro o imagen dentro de las fronteras de aquel país, o al menos no tan difundida.

Sin embargo, existía otra cara, y estaba en alemán, accesible por lo tanto a un público más amplio y extramuros del Instituto Ibero-Americano. Me refiero a la cara que habían configurado ciertas traducciones de nuestra poesía que habían llegado para entonces a la nación germana. De la misma manera, la poesía costarricense había llegado ya y para entonces a diversos entornos de habla inglesa, como también a contextos de habla francesa, sueca, rumana, italiana, o incluso hebrea. Todo esto a través de iniciativas traductoras, que en la mayoría de los casos habían resultado ser iniciativas aisladas, individuales, asistemáticas, y sin control alguno por parte de nuestro entorno.

Así, nuestra poesía sítiene una imagen externa, mínima tal vez, pero es un rostro internacional del cual no estamos del todo conscientes y sobre cuya configuración no parece que hayamos tenido ningún tipo de injerencia. Ante esa situación: ¿qué muestra esa imagen de nuestra producción lírica en el exterior? ¿Se asemeja a la que nosotros mismos reconocemos dentro de nuestras fronteras? ¿Cómo se visualiza la poesía costarricense en el exterior?

Estas, entre otras interrogantes, apuntan a un tema de carácter más general, que tiene que ver con la relación entre el fenómeno de la traducción y la construcción de la imagen que la literatura de un país dado puede alcanzar en el exterior. Voy a aproximarme al asunto, por supuesto, a través del caso de las traducciones de poesía costarricense producidas durante el siglo, con dos objetivos: primero, mostrar cómo la traducción puede configurar la imagen externa de la tradición literaria de un país, sobre todo cuando se trata de una literatura periférica 
y, segundo, en el caso de la poesía costarricense, describir su imagen externa y contraponerla a la imagen interna.

Desarrollaré el tema en tres partes: la primera, una breve descripción del panorama histórico-poético de la poesía del país, y contar con un marco de referencia con el cual comparar posteriormente la imagen externa que tiene nuestra poesía. La segunda, un recuento de las publicaciones en que se movilizó la poesía costarricense hacia diversas lenguas, lugares y momentos durante el siglo xx. La tercera, una descripción de la imagen que ha adoptado la poesía costarricense en el exterior, en contraposición a la imagen propia, así como las consecuencias que tal situación puede haber tenido.

Hagamos un breve paréntesis para definir lo que entiendo como literaturas periféricas. Son estas pues, todas aquellas literaturas que tradicionalmente no han entrado en el canon literario occidental: dígase las literaturas de los ámbitos coloniales y poscoloniales, las de los grupos marginados y marginales, o, generalizando aun más, las literaturas de los colectivos minoritarios, entendidos estos como todos aquellos grupos que históricamente no han ocupado posiciones de poder.

\section{Las caras de la poesía costarricense}

Debemos iniciar el recuento de lo que se puede considerar poesía costarricense propiamente dicha en las postrimerías del siglo xix. Surge en aquel momento, para llegar a consolidarse como un elemento propiamente costarricense solo hasta los primeros años del siglo xx. Al respecto, cabe mencionar, solo de paso y según nos indica el estudioso e historiador de la literatura costarricense Álvaro Quesada Soto ${ }^{3}$, que durante la colonia, pasada la independencia (en 1821) e incluso bien entrado el siglo xix, la producción literaria en Costa Rica no fue una actividad que pueda considerarse como relevante. Esto, por un lado,

3 Álvaro Quesada Soto, Breve historia de la literatura costarricense (San José: Editorial Costa Rica, 2008) 15 . 
dado que las publicaciones en lo que llegaría a ser el territorio nacional se limitaban en su mayoría a textos de corte didáctico, religioso o político y, por otro lado, porque nunca existió un verdadero entorno, ni editorial ni de publicaciones, que se prestase para la producción literaria durante aquel periodo. Apunta Quesada Soto que

solamente el cuadro de costumbres [tuvo] algún desarrollo consistente antes de finales de siglo [xix], concebido a imitación de Mariano José de Larra y del costumbrismo español e hispanoamericano, como descripción o comentario humorístico, pintoresco o satírico, de las costumbres sociales y políticas. (...) Solo a finales del siglo xix se aprecia ya [en ciertos sectores de la sociedad] una preocupación por producir una literatura nacional costarricense.

\section{La periodización}

Para distinguir los diferentes rostros que ha mostrado la poesía costarricense, me voy valgo de la descripción generacional establecida por el poeta, filólogo y profesor de esta Universidad Nacional, Carlos Francisco Monge, quien ha identificado y agrupado diferentes sistemas de preferencias temáticas, discursivas y retóricas en el panorama histórico de la lírica costarricense. Justifico esta decisión a partir del hecho de que constituye el estudio más actual y amplio dedicado a la poesía de Costa Rica y se encuentra en sus obras (vid. Monge, 1984, 1987, 1991, 1992, 1999 у 2005) .

\section{Las generaciones}

No sin antes advertir sobre el carácter aproximado y fluctuante de las fechas establecidas, distingue dos grandes períodos en la poesía

4 Carlos Francisco Monge, La imagen separada. Modelos ideológicos de la poesía (1950-1980) (San José: Ministerio de Cultura, Juventud y Deportes, 1984); «La escritura: pasión de la historia. La poesía contemporánea de Costa Rica» Revista Iberoamericana, LIII, 138-139 (1987): 303323; Códigos estéticos de la poesía de Costa Rica (1907-1967) (Tesis. Madrid: Universidad Complutense de Madrid, 1991); Antología crítica de la poesía de Costa Rica (San José: Editorial de la Universidad de Costa Rica, 1992); La rama de fresno: Ensayos sobre la literatura en Costa Rica (Heredia: EUNA, 1999); y El vanguardismo literario en Costa Rica (Heredia: EUNA, 2005). 
costarricense: el primero va desde el año 1900 hasta 1940, y es denominado «período modernista». El segundo, que abarcaría los años entre 1940 e inicios de la década de 1990, se denomina «período de vanguardia» (Monge, 1991 y 1992).

Ahora bien, entre ambos periodos, están distribuidas cinco generaciones poéticas que han configurado el universo lírico del país. Tales generaciones han sido designadas como la generación modernista, la generación posmodernista, la prevanguardista, la vanguardista y la posvanguardiasta. Las primeras tres habrían surgido durante el periodo modernista y las dos últimas más bien dentro del periodo de vanguardia (Monge, 1991 y 1992).

No me detengo ahora en dichos periodos, sino que paso directamente a describir de manera muy sucinta las cinco generaciones mencionadas.

\section{La generación modernista}

La generación modernista, constituida, según Monge, por poetas nacidos entre 1874 y 1897, y entre quienes figuran Roberto Brenes Mesén, Rafael Ángel Troyo, Eduardo Calsamiglia, Lisímaco Chavarría, Rafael Cardona, Rogelio Sotela, Manuel Segura Méndez, y sólo parcialmente, Julián Marchena y José Basileo Acuña (Monge, 1992: 17).

Sentían estos poetas modernistas un fuerte rechazo hacia el costumbrismo literario y tendían a idealizar la realidad que percibían como semejante al arte (Monge, 1991: 50-51). Sus temas se vinculan a lo prosaico de la realidad inmediata, al arte, a la hispanidad y el americanismo, al exotismo y a las mitologías clásicas y, al mismo tiempo, el cosmopolitismo, la armonía y la belleza son centrales para su quehacer en términos ideológicos.

Los modernistas prefieren lo sensorial y el lenguaje cosmopolita, culto, extraño y ajeno al entorno inmediato, tendente a lo inusitado y opaco. Rechazan las formas coloquiales y regionales. Su estilo es poético, más bien alejado del entorno lingüístico nacional, y favorecen la 
repetición y el ordenamiento sintáctico de tipo inusual (Monge, 1991: 131). Se decantan también por utilizar imágenes foráneas, exóticas y ajenas a la realidad inmediata (Monge, 1991: 50). Es de rigor señalar también que los poetas modernistas costarricenses adoptan, en buena medida, las matrices convencionales en cuanto a estrofa, rima, ritmo y verso (Monge, 1991: 130).

\section{La generación posmodernista}

Dela segundageneración, la posmodernista, participan los poetas nacidos entre 1897 y 1907. Entre ellos usualmente se nombra a Julián Marchena, Rafael Estrada, Arturo Agüero, Carlos Luis Sáenz, Asdrúbal Villalobos y Max Jiménez; éste también llegará a formar parte de la siguiente generación, la de prevanguardia (Monge, 1992: 19-22).

Al contrario de los modernistas, el posmodernismo fue un movimiento orientado hacia la interioridad, lo inmediato, lo concreto, la patria, lo provincial y lo cotidiano, la presencia de lo urbano en contraposición a lo rural, y la vuelta a lo primigenio asociado a la idea de nación. También resultó ser una crítica a la suntuosidad, a la lejanía sociopolítica y al cosmopolitismo modernista de la generación anterior (1991: 51-54).

En lo estilístico tienden al prosaísmo y a la repetición, y a una cierta ambigüedad entre la tradición y lo «propio». El lenguaje en ellos se torna simple, cotidiano y popular; incluso coloquial y regional; espontáneo y claro. Sus imágenes emulan lo familiar y lo local al tiempo que se muestran racionales al dar cuenta del entorno inmediato (Monge, 1991: 54, 217-219).

En cuanto a patrones convencionales, los posmodernistas se muestran más bien algo ambivalentes: en ellos resulta tan usual el uso de matrices de ritmo y tipo de verso como las irregularidades en aquellos mismos rasgos y, al tiempo que revalorizan los patrones estróficos populares, tienden también a romper con tales patrones (Monge, 1991: 55, 210-214). 


\section{La generación prevanguardista}

La generación de prevanguardia, la tercera según el orden establecido, está compuesta por poetas nacidos entre 1907 y 1917. Entre ellos usualmente se incluye a Max Jiménez, Francisco Amighetti, Fernando Centeno Güell, Arturo Echeverría Loría, Isaac Felipe Azofeifa, Fernando Luján, Alfredo Cardona Peña y Alfonso Ulloa Zamora (Monge, 1992: 22).

No son tan marcadas las diferencias entre esta y la generación anterior ${ }^{5}$; sin embargo, es notorio que sus miembros cambian la tranquilidad por la incertidumbre (Monge, 1991: 248) y radicalizan así las rupturas propuestas por el posmodernismo (Monge, 1992: 23).

Se destacan entre sus temas la transitoriedad de una realidad siempre vertiginosa, fugaz y efímera, el pesimismo existencial, la ciudad como símbolo de lo efímero de la existencia, la soledad del ser y la palabra como forma de dar sentido al mundo (Monge, 1991: 249-276).

El estilo de los poetas prevanguardistas costarricenses tiende al prosaísmo al tiempo que muestran inclinación por la anáfora y la reiteración. Las obras de este grupo dejan ver un lenguaje opaco y extraño al entorno inmediato. Con ellos y sus obras incursiona la imagen irracional y fragmentada en la lírica costarricense (Monge, 1991: 300-310). Por otro lado, el versolibrismo y un marcado desarraigo con respecto a los patrones convencionales de rima, ritmo, verso y estrofa son otras de las marcas características que se han reconocido en la obra de esta generación (Monge, 1991: 298-300).

\section{La generación vanguardista}

Llegamos así a la cuarta generación, la de vanguardia, bifurcada en dos generaciones. La primera incluye a poetas nacidos entre 1917 y 1927. Entre ellos se encontraban Eunice Odio, Alfredo Sancho, Arturo Montero Vega, Salvador Jiménez Canosa, Victoria Urbano

5 Véase Monge, 1991: 53. 
y Eduardo Jenkins Dobles, que cobran vigencia entre 1950 y 1960 (Monge, 1992: 25).

Por su parte, la segunda generación de vanguardia estaba integrada por Mario Picado, Jorge Charpentier, Ana Antillón, Virginia Grütter, Raúl Morales, Carmen Naranjo, Carlos Luis Altamirano, Ricardo Ulloa Barrenechea y Carlos Rafael Duverrán, quienes nacieron entre 1927 y 1937. Es con ellos que se consolida el vanguardismo poético en Costa Rica (Monge, 1992: 26).

En términos temáticos, estas generaciones abordan asuntos relacionados con el anhelo de comunicación, la disolución del sentido y la condición del ser ante el mundo.

Su estilo es prosaico con una marcada tendencia a la yuxtaposición y a la fragmentación; su lenguaje es inusual y ajeno al entorno, inédito y poco convencional, altiempo que muestran un amplio registro léxico; sus imágenes resultan irracionales e insólitas. Privilegian las formas abiertas y libres, y rompen totalmente con las matrices convencionales relativas a la rima, el ritmo, el verso y la estrofa (Monge, 1991: 330-391).

\section{La generación de posvanguardia}

Cierro este recuento con la quinta generación, la de posvanguardia, que como la anterior también se subdivide, en tres grupos (Monge, 1991: 403-410).

En la primera de ellas, visible ya hacia la segunda mitad de los años sesenta, se incluye principalmente a Jorge Debravo, Mayra Jiménez,LaureanoAlbán, JulietaDobles Yzaguirre, MarcoAguilar, Germán Salas y Alfonso Chase, Rodrigo Quirós, Guillermo Sáenz Patterson, Rosita Kalina, Carlos de la Osa y Juán Antillón (Monge, 1992: 2930). Con ellos llega la poesía social al ámbito poético costarricense.

La segunda generación de posvanguardia estaría activa a partir del segundo lustro de 1970 y la integran Leonor Garnier, Carlos de la Osa, Luis Kleiman, Osvaldo Sauma, Ronald Bonilla, Carlos Francisco Monge, Lil Picado, Diana Ávila, Rodolfo Dada, Mía Gallegos y Nidia 
Barboza, aunque también Miguel Fajardo, Erick Gil Salas, Gerardo Morales y Milton Zárate (Monge, 1992:32).

Finalmente, ya hacia la segunda mitad de la década de 1980 surge la tercera generación posvanguardista. Ellos serán Jorge Arroyo, Macarena Barahona, Carlos Cortés, Gabriela Chavarría, Guillermo Fernández, Víctor Hugo Fernández, Ana Istarú, Vernor Muñoz, Armando Antonio Ssacal, Habid Succar y Milton Zárate (Monge, 1992: 34).

Estos poetas filtran yrepresentanel mundo según unaperspectiva ideológica fundamentada en un componente ético-político (Monge, 1991: 407). Su obra aborda la realidad social circundante, sustituye lo abstracto por lo concreto, confiere una actitud crítica y humanista a la práctica literaria en relación con el ambiente social y los valores, resta importancia a la individualidad en favor de la colectividad y retorna a lo esencialmente humano (Monge, 1991:408).

$\mathrm{Su}$ discurso es sencillo y simplificado, y su estilo claro y, con cierto prosaísmo, sin renunciar por completo al lenguaje poético. Favorecen también el lenguaje doméstico, cotidiano y coloquial. Sus imágenes son más bien familiares, racionales y realistas (Monge, 1991: 403, 438).

Con estas breves notas sobre la poesía posvanguardista costarricense acaba el recuento del panorama histórico-poético del país, esto es, de las cinco caras que tuvo nuestra poesía desde sus inicios hasta finales del siglo pasado. Ya lo traeré a colación una vez más, hacia el final de esta exposición, cuando lo contraste con su cara externa, esto es, aquella que le ha sido dada por medio de la traducción.

\section{Las lenguas, los lugares y los momentos}

Dicho esto, abordemos ahora el asunto de las lenguas, momentos y lugares a los que ha llegado la poesía de nuestro país, así como el de las publicaciones concretas por medio de las cuales se ha movilizado. 
Empecemos por este último: las publicaciones o traducciones. En 2007 se contaban 32 publicaciones en las cuales se pudo determinar (Vargas Gómez, 2012) que se incluyeron traducciones de poesía costarricense. No obstante, por el momento solamente se han podido estudiar 26 de ellas. De esas 26 obras, 18 son de carácter antológico, la mayoría dedicadas a la poesía latinoamericana o centroamericana, y las restantes 8 son más bien de carácter monográfico, entre las que destacan, por su cantidad, las traducciones de varios poemarios de Laureano Albán.

Ahora bien, la distribución lingüística, geográfica y temporal de aquellas 26 obras permite agruparlas en ocho diferentes grupos que presento a continuación.

\section{Las traducciones al alemán: Austria, la década de 1990}

El primero lo conforman dos traducciones al alemán, que surgieron en Austria a inicios de los años 90.

La primera de ellas, titulada AMORica Latina ${ }^{6}$ y publicada en 1991, presenta al lector un conjunto de obras escritas originalmente por 27 autoras latinoamericanas y traducidas por la profesora e investigadora de origen austriaco, Erna Pfeiffer. En esta obra se incluyeron las traducciones de tres poemas de la poetisa costarricense Ana Istarú.

En la segunda, de título Torturada ${ }^{7}$ y publicada en 1993, se vuelven a incluir poemas de Istarú, dos en número y de carácter más bien político, provenientes del poemario La muerte y otros efímeros agravios $^{8}$. Al igual que AMORica Latina, Torturada consiste en un conjunto deobras escritas originalmente por autoras latinoamericanas, también traducidas por la profesora Pfeiffer.

6 Erna Pfeiffer (ed.), AMORica Latina. Mein Kontinent - Mein Körper. Erotische Texte lateinamerikanischer Autorinnen (Viena: Wiener Frauenverlag, 1991).

7 Erna Pfeiffer (ed.), Torturada. Von Schlächtern und Geschlechtern. Texte lateinamerikanischer Autorinnen zu und politischer Gewalt (Viena: Wiener Frauenverlag, 1993).

8 Ana Istarú, La muerte y otros efímeros agravios (San José: Editorial Costa Rica, 1989). 


\section{Las traducciones al francés: Francia, las décadas de 1980 y 1990}

Paso ahora al segundo grupo: las cuatro traducciones al francés que surgieron en tierras galas durante las décadas de 1980 y 1990.

La primera de ellas corresponde a la obra de tipo antológico titulada, y los colegas de francés sabrán perdonarme la mala pronunciación, Poésie costaricienne du xx $x^{e}$ siècle ${ }^{9}$. Publicada en 1997 y con el escritor nacional Carlos Cortés como editor a cargo, esta antología incluye traducciones de la poesía de una treintena de poetas ticos.

La segunda publicación de este grupo corresponde al título Saison de fièvre ${ }^{10}$, traducción de La estación de fiebre ${ }^{11}$, de Ana Istarú. Bilingüe y evidentemente monográfica, esta obra incluye 33 poemas originales con sus respectivas traducciones.

Les Belles Étrangères: 14 écrivains d'Amérique Centrale ${ }^{12} \mathrm{es}$ la tercera de este grupo de publicaciones. Este volumen, de carácter antológico y publicado en 1997, está compuesto por las traducciones de la poesía de 14 escritores centroamericanos (tal y como su título lo indica). Entre ellos también se encuentran las traducciones de cuatro poemas de Ana Istarú.

La cuarta y última publicación de este grupo, surgida en 2002, se titula Une Anthologie de Rencontres ${ }^{13}$. La obra incluye las traducciones de unas cinco decenas de poetas de diverso origen geográfico, entre ellas se incluyeron cuatro realizadas a partir de poemas Ana Istarú.

\section{Las traducciones al inglés: Canadá, Estados Unidos, Inglaterra y Costa Rica}

El tercer grupo está compuesto por las traducciones al inglés, las cuales a su vez se subdividen en cuatro diferentes subgrupos a partir de su lugar de origen: las que surgieron en Canadá, las que aparecieron

\footnotetext{
9 Carlos Cortés (ed.), Poésie costarricienne du xxe siécle (Ginebra, Suiza: Editions Patiño/Union Latine, 1997).

10 Ana Istarú, Saison de fièvre (París: La Diffférence/Éditions UNESCO, 1997).

11 Ana Istarú, La estación de fiebre (San José: Editorial Universitaria Centroamericana, 1983).

12 s.e., Les Belles Étrangères: 14 écrivains d'Amerique Centrale (s.1.: Centre national du livre, 1997).

13 Henri Deluy (ed.), Une Anthologie de Rencontres (Tours: Éditions Farrago, 2002).
} 
en Estados Unidos, las que se publicaron en Inglaterra y una más que apareció aquí mismo en Costa Rica.

Canadá es el contexto de publicación de una sola de aquellas veintiséis obras. Titulada The Raddle Moon 4. International Women Writers Issue ${ }^{14}$ y publicada en 1986, aquel volumen de carácter antológico, en el que se incluían obras escritas por mujeres procedentes de cuatro diferentes continentes, contenía una vez más, la traducción de un poema escrito por Ana Istarú.

Pasando al ámbito nacional encontramos una única publicación. También escrita en lengua inglesa, Gallop of Lights ${ }^{15}$ es la traducción del poemario Galope de luces, de Floria Herrero Pinto. Dicha traducción, de naturaleza monográfica y en formato bilingüe, surge en 1992 y consta de veinticuatro poemas traducidos al inglés por Liz Lambert Martén ${ }^{16}$.

Repasemos el tercer subgrupo de traducciones al inglés. Me refiero a las publicaciones que se produjeron en los Estados Unidos, a partir de 1968 y hasta 2007. La primera de ellas, titulada Young Poetry of the Americas ${ }^{17}$, fue precisamente la que se produjo en 1968, bajo el auspicio de la Secretaría General de la Organización de Estados Americanos. Dedicado por completo a la poesía latinoamericana, el volumen de tipo antológico incluye traducciones de la poesía de Jorge Debravo, Jorge Ibáñez, Laureano Albán, Julieta Dobles Yzaguirre, Marco Aguilar, Rodrigo Quirós, Alfonso Chase y Arabella Salaberry.

Contemporary Costa Rican Literature in Translation: A Sampler of Poetry, Fiction and Drama ${ }^{18}$ es la segunda de las publicaciones que surgió en el contexto estadounidense. En esta obra, de carácter

14 Susan Clark (ed.), The Raddle Moon 4. International Women Writers Issue (Vancouver: s.e., 1986).

15 Floria Herrero Pinto, Galope de Luces/Gallop of Lights (San José, Costa Rica: Círculo de Escritores Costarricenses en cooperación con los Cursos de Teoría y Práctica de la Creación Literaria de la Escuela de Filología y Lingüística, Facultad de Letras, Universidad de Costa Rica, 1992).

16 Por aquel entonces cuñada de Herrero Pinto.

17 General Secretariat of the Organization of American States, Young Poetry of the Americas (Washington, D.C.: Organization of American States. General Secretariat, 1968).

18 Ervin Beck y Wilbur Birky (eds.), Contemporary Costa Rican Literature in Translation: A Sampler of Poetry, Fiction and Drama (Indiana: Pinchpenny Press, 1975). 
antológico, publicada en 1975 y dedicada, como su título lo indica, totalmente a la literatura costarricense, se incluyeron traducciones de la poesía de Julián Marchena, José Bacileo Acuña, Isaac Felipe Azofeifa, Mario Picado, Alfonso Chase, Carlos Francisco Monge y Ronald Bonilla.

La tercera en la lista es una publicación, también de naturaleza antológica, publicada en 1975 y titulada Mundus Artium. A Journal of International Literature and the Arts (Central American Selection) ${ }^{19}$. En ella se incluyó un grupo de traducciones de obras de Laureano Albán, Alfonso Chase, Luis Fernando Charpentier (Charpan), Mario Picado, Ana Antillón, Ronald Bonilla y Carmen Naranjo.

Le sucede a dicha obra un modesto tomo publicado en 1977 y titulado Dos elegías: Two elegies ${ }^{20}$. En ella se incluye, en versión bilingüe, la elegía que Alfredo Cardona Peña escribiera en conmemoración de su padre, fallecido.

Autumn's Legacy ${ }^{21}$ es el título de la quinta publicación de las que surgieron en los Estados Unidos. Traducción completa del libro Herencia de otoño ${ }^{22}$, de Laureano Albán, esta obra en versión bilingüe, incluye las traducciones de veintinueve poemas y se publicó en 1982.

La traducción de otro título original de Albán constituye la sexta publicación de este grupo. Producida en 1984, The Endless Voyage ${ }^{23}$, traducción de El viaje interminable ${ }^{24}$, incluye las traducciones de treinta poemas, antecedidas todas por sus originales.

Llegamos así a la sétima publicación con sello estadounidense; hablo pues de una antología dedicada a la poesía de mujeres

19 Rainer Schulte (ed.), Mundus Artium. A Journal of International Literature and the Arts (Central American Selection) (Ohio: International Poetry Forum, 1975).

20 Alfredo Cardona Peña y Álvaro Cardona-Hine, Dos elegías: Two elegies (Los Ángeles y Fairfax: The Red Hill Press, 1977).

21 Laureano Albán, Autumn's Legacy (s.1.: Ohio University Press, 1982).

22 Herencia de otoño (Madrid: Rialp, 1980).

23 Laureano Albán, The Endless Voyage (Ohio: International Poetry Forum/Ohio University Press, 1984).

24 Laureano Albán, El viaje interminable (Madrid: Ediciones Cultura Hispánica del Instituto de Cooperación Iberoamericana, 1983). 
latinoamericanas, surgida en 1987 y titulada Ixoc Amar · Go: Central American Women's Poetry for Peace ${ }^{25}$. Entre las traducciones de las 56 poetisas antologadas se encuentran las de poemas originalmente escritos por Virginia Grütter, Carmen Naranjo, Leonor Garnier, Celina García, Mayra Jiménez, Julieta Dobles, Janina Fernández, Mía Gallegos, Diana Ávila y Ana Istarú.

En 1989 se publica, una vez más, una traducción completa de uno de los poemarios de Laureano Albán. Bajo el título Summa of Clarities $^{26}$ — traducción al inglés del original Suma de claridades ${ }^{27}$ esta obra incluye las traducciones de los quince poemas que conforman el texto original.

Alcanzamos de tal forma la década de 1990 y la primera traducción vertida al inglés en los Estados Unidos durante aquellos años es el título Pleasure in the World. Erotic Writing by Latin American $W_{o m e n}{ }^{28}$. Publicada en 1993, esta antología recoge las traducciones del trabajo de 32 poetisas latinoamericanas. Entre ellas se incluyen traducciones de la poesía de Ana Istarú.

La décima publicación en este grupo es These Are Not Sweet Girls. Latin American Women Poets ${ }^{29}$. Publicada en 1994, en ella nuevamente se integra, mediante la traducción, la obra de 53 poetisas de origen latinoamericano. En cuanto a la poesía costarricense, una vez más se incluyeron sobre todo traducciones de la poesía de Ana Istarú, aunque también de Rosita Kalina y de Eunice Odio.

La siguiente publicación vuelve a implicar una obra completa del poeta Laureano Albán. De título Encyclopedia of Wonders/de

25 Zoë Anglesey (ed.), Ixoc Amar · Go: Central American Women's Poetry for Peace (Penobscot: Granite Press, 1987).

26 Laureano Albán, Summa of Clarities (Madrid: Fundación Fernando Rielo, 1989).

27 Laureano Albán, Suma de claridades (Sevilla: s.e., 1992).

28 Margarite Fernández Olmos y Lizabeth Paravisini-Gebert (eds.), Pleasure in the World. Erotic Writing by Latin American Women. (Nueva York: White Pine Press, 1993).

29 Marjorie Agosín (ed.), These Are Not Sweet Girls. Latin American Women Poets (Fredonia, Nueva York: White Pine Press, 1994). 
Maravillas $^{30}$ y publicada en 1995, esta traducción de índole monográfico comprende unas 1500 páginas distribuidas en tres tomos.

La duodécima publicación en la lista de traducciones al inglés producidas dentro de las fronteras estadounidenses se publicó en 1996 bajo el título Twentieth-Century Latin American Poetry: A Bilingual $A n t h o l o g y^{31}$. En ella se incluyeron traducciones de tres poemas y una carta de Eunice Odio.

El penúltimo volumen de este grupo incluye la traducción de un único soneto de Jorge Debravo. Dedicada totalmente al tema del amor, The Best One Hundred Love Poems of the Spanish Language ${ }^{32}$ se publica en 1998 en Nueva York, bajo la dirección editorial de Pedro Lastra y Rigas Kappatos.

Finalmente, la décimo cuarta publicación en este caso resulta bastante cercana a todos nosotros en cierto sentido. Se trata de Invisible Ink ${ }^{33}$, traducción completa de la obra La tinta extinta ${ }^{34}$ de Carlos Francisco Monge y cuyo traductor fue Victor Drescher, profesor colaborador desde hace ya más de un decenio de la Escuela de Literatura y Ciencias del Lenguaje.

El cuarto subgrupo de traducciones al inglés está constituido por dos traducciones producidas en Inglaterra. La primera de ellas, publicada en 1987, se tituló The Renewal of The Vision: Voices of Latin American Women Poets 1940-198035. En ella se incluyeron traducciones de cinco poemas de Rosita Kalina y dos de Eunice Odio.

30 Laureano Albán, Encyclopedia of Wonders/de Maravillas (Pittsburgh: International Poetry Forum, 1995).

31 Stephen Tapscott (ed.), Twentieth-Century Latin American Poetry: A Bilingual Anthology (Austin: Texas University Press, 1996).

32 Pedro Lastra y Rigas Kappatos (eds.), The Best One Hundred Love Poems of the Spanish Language (Nueva York: Seaburn, 1998).

33 Carlos Francisco Monge, Invisible Ink (Heredia: Escuela de Literatura y Ciencias del Lenguaje, Universidad Nacional, 2007).

34 Carlos Francisco Monge, La tinta extinta (San José: EDUCA, 1990).

35 Marjorie Agosín y Cola Franzen (eds.), The Renewal of The Vision: Voices of Latin American Women Poets 1940-1980 (Peterborough: Spectacular Diseases, 1987). 
La segunda, surgida en 1989, titulada Lovers and Comrades: Women's resistance poetry from Central America ${ }^{36}$, presenta traducciones de la obra de numerosas poetisas latinoamericanas (a pesar de la referencia al área centroamericana que se hace en el título), entre ellas Janina Fernández, Eulalia Bernard, Lilly Guardia y Ana Istarú.

\section{Las traducciones al rumano: Rumanía, la década de 1970}

Reseñado yael grupo de publicaciones que incluían traducciones de poesía costarricense al inglés, delimito ahora el sétimo grupo, que está compuesto por una única traducción, esta vez al rumano: Poezie contemporana din Costa Rica, de Darie Novaceannu. Dicho volumen se publicó en 1975 y, siendo de tipo antológico, incluyó traducciones de la poesía de veinticuatro poetas de nuestro país.

\section{Las traducciones al sueco: Suecia, la década de 1990}

Finalmente, el octavo y último grupo está constituido también por un único ejemplar: Stigar/Senderos. Dikter från Centralamerika/ Poesía de Centroamérica ${ }^{37}$, traducción al sueco publicada en 2003. En ella se incluyeron traducciones de seis poemas de las poetisas Ana Istarú, María Montero y Alejandra Castro. Con la reseña de esta traducción al sueco, doy por terminado el recuento de los lugares, momentos, lenguas y medios a los que llegó nuestra poesía a lo largo del siglo pasado.

\section{Las caras adoptadas por la poesía costarricense en el exterior y la imagen que de ella proyectan}

Abordo ahora el tercero de los puntos a los que me referíal empezar; esto es, la cuestión de las caras que ha adoptado la poesía costarricense en el exterior y la imagen que de ella proyectan tales rostros.

36 Amanda Hopkinson (ed.), Lovers and Comrades: Women's Resistance Poetry from Central America (Londres: The Women's Press, 1989).

37 Luz Lescure (ed.), Stigar/Senderos. Dikter från Centralamerika/Poesía de Centroamérica (s.1.: Biblioteca Real de Suecia, 2003). 


\section{La poesía traducida}

Ante todo, voy a referirme al material traducido; esto es, al tipo de poesía costarricense que se tradujo. Al respecto, cabe decir que la poesía traducida, esto es, los poemas originales, se vinculaban en el aspecto generacional a las tendencias posvanguardistas de la poesía costarricense en más de un $92 \%$, al tiempo que mostraban ligámenes con las vanguardias ticas hasta en un $30 \%$. Mucho más modestas son la cifras que muestran lazos con las demás generaciones: en un 11,53 $\%$ con respecto a la prevanguardia y al posmodernismo, y solamente un $7,69 \%$ se vinculaba al modernismo.

En cuanto al eje temporal, se puede decir que los originales traducidos se ubican en el ámbito de lo contemporáneo, ya que el $96 \%$ de ellos se habían publicado durante la segunda mitad del siglo pasado. Para acabar con esta instantánea, me refiero a la cuestión temática: lo cierto es que la poesía que se tradujo trataba sobre todo temas de índole femenina y feminista o social y sociopolítica, en alrededor de un $58 \%$ y $38 \%$ de los casos, respectivamente. Lo anterior, como ya se señaló, representa el perfil de aquello que se tradujo. Pero, ¿qué fue entonces lo que no llegó a traducirse?

\section{Lo que no se tradujo: la cara oculta}

Desde una aproximación generacional, la poesía costarricense que menos se ha traducido es modernista, posmodernista o prevanguardista. Eso implica que la imagen externa de la poesía costarricense haya quedado necesariamente incompleta.

En términos temáticos tal hecho anterior implicó que se dejara de lado aquella parte del panorama poético costarricense que aborda temas relacionados con el mundo como realidad idealizada, el cosmopolitismo y la búsqueda de la armonía, populares entre los poetas modernistas. Asimismo no se incluyeron los temas comunes entre la generación posmodernista, centrados enelentorno inmediato, presente y urbano en oposición al mundo rural, en la modernización del entorno asociado a lo privado, la melancolía, el tiempo y lo efímero, en la 
realidad difusa, ni en la vuelta a lo primigenio como visión asociada a la idea de nación. Finalmente, se excluyen — aunque en menor medida que en los dos casos anteriores - los núcleos temáticos preferidos por los prevanguardistas, que giraban alrededor de lo transitorio de una realidad vertiginosa, fugaz y efímera, del pesimismo existencial, de la ciudad como símbolo de una existencia efímera y de la soledad del ser, y de la palabra como forma de dar sentido al mundo.

En cuanto a lo formal, se eludió traducir aquella poesía que favorecía el uso constante de patrones «convencionales» de rima, métrica o estrofa, muy gustados por los modernistas. En esa misma línea, también se evitó traducir ciertas manifestaciones que ya en su época presentaban alguna tendencia a las irregularidades formales (las posmodernistas) pero también a otras cuyo desarraigo para con las formas «convencionales» era ya bastante pronunciado (las prevanguardistas).

En la dimensión lingüística, se tradujeron mucho menos aquellas manifestaciones que favorecieran un lenguaje opaco, rico en términos léxicos, insólito o extraño al entorno lingüístico inmediato, preferido por los prevanguardistas. La poesía modernista, que hacía uso de un lenguaje culto, de corte poético y artístico, y sintácticamente inusual también fue relegada en un alto porcentaje. Por otro lado, tampoco se tuvo a bien seleccionar aquellas obras posmodernistas, que hacían gala de un lenguaje de tipo popular, regional y espontáneo.

No se favoreció tampoco la poesía que presentaba imágenes de índole foránea o exótica, ajenas a la realidad sociohistórica inmediata, frecuentes entre los modernistas. Se evitó aquella poesía que recurría a imágenes que no solo eran locales sino que además apelaban a lo tradicional y al pasado con cierta nostalgia, preferidas por los posmodernistas. La poesía que acudía a imágenes con algunos dejos de irracionalidad y fragmentación, comunes entre los prevanguardistas, también fue relegada, aunque en este caso el rechazo no fue tanmarcado.

En cuanto a lo temporal, las menos traducidas fueron aquellas manifestaciones más tempraneras; esto es, las modernistas y posmodernistas. Aunque en menor grado, la poesía prevanguardista, más 
contemporánea que los dos casos anteriores, también quedó entre las menos traducidas. Como es notorio, estos tres grupos corresponden a la poesía costarricense producida principalmente durante la primera mitad del siglo $\mathrm{xx}$.

\section{La configuración de las traducciones}

Conociendo el tipo de poesía que se tradujo y aquella que no llegó a traducirse, o al menos que se tradujo en menor cantidad, me ocupo ahora de dos asuntos fundamentales para el tema de esta intervención: el primero consiste en delinear el perfil formal y temático de las traducciones propiamente dichas, en otras palabras, lo que las traducciones dejan ver a partir de sí mismas. El segundo, que a todas luces es el de mayor interés y que me tiene hoy frente a ustedes, implica dibujar la imagen que dichas traducciones proyectan sobre la poesía costarricense en el ámbito internacional.

Me ocupo entonces del primero: de la configuración formal y temática que exhiben las traducciones. En cuanto a los temas - y como un reflejo cercano de las temáticas presentes en los textos originales traducidos - en las traducciones es evidente que se aborda la cuestión femenina y feminista, en un $73 \%$ de los casos, así como los asuntos de índole social y sociopolítica, en más de un $61 \%$ de las ocasiones. Tratan también otras temáticas de tipo surrealista, humano o humanista, trascendentalista y subjetiva, pero solo de manera secundaria.

Con respecto a las formas convencionales, las traducciones en su conjunto muestran un claro distanciamiento con respecto a patrones fijos de rima, medida del verso o configuración estrófica, en casi un $90 \%$ de los casos, mientras que solo en un 11,5\% de las traducciones hay una tendencia a lo convencional; no obstante, incluso en tales ocasiones es leve o muy leve.

Finalmente, las traducciones presentan una configuración lingüística también muy similar a la de los textos originales. En otras palabras, favorecen en su gran mayoría un lenguaje que transita entre lo cotidiano y lo inusual, y que va de lo elaborado a lo sencillo. 
Tal configuración, que como ya se ha sugerido «retrata» en muy buena medida la de los poemas originales, sería la resultante del instrumentalismo y del mimetismo traductores, aplicados durante el proceso traductor en todos los casos. Tales principios implicaron que se intentó reproducir los rasgos de los poemas originales a excepción de aquellos rasgos más apegados a las formas convencionales, en otras palabras, las rimas, los ritmos y los patrones de estrofa.

\section{La cara o imagen externa}

En cuanto al segundo asunto, develar la imagen que dichas traducciones proyectan en el ámbito internacional, cabe concluir que el tipo de poesía traducido y la manera en que se tradujo dieron como resultado que se proyecte a la poesía costarricense de dos maneras: primero, no como una tradición poético-literaria independiente, sino como una manifestación siempre asociada, en presunta armonía y hasta cierto punto dependiente de tradiciones líricas más amplias, antiguas o conocidas (la poesía centroamericana, la poesía latinoamericana o la poesía hispanoamericana) y, segundo, como una poesía que se ocupa casi exclusivamente de asuntos de tipo social, sociopolítico, femenino y feminista, que prácticamente ha descartado o que inclusive no ha experimentado del todo con las formas convencionales relativas a la rima, medida del verso o estrofa, y que utiliza casi de manera exclusiva un lenguaje que mezcla lo sencillo y cotidiano (sobre todo en términos léxicos) con uno que sintácticamente es elaborado y pocofrecuente.

\section{¿Qué repercusiones pudieron haber tenido tales hechos?}

Cabe especular sobre las repercusiones que pudo haber tenido aquella imagen, por lo demás inexacta y parcializada de la poesía costarricense. La primera es que la imagen que se pudo haber tenido de nuestra poesía en los entornos a los que llegaron sus traducciones habrá estado obligatoriamente sesgada, y no respondería a la lógica de su desarrollo histórico o poético. 
Aquella imagen la habría reducido a una poesía esencialmente militante o de combate - feminista o revolucionaria - formalmente posvanguardista. Asimismo, habría anulado de golpe la existencia de las manifestaciones más «convencionales» de la tradición lírica costarricense, así como de gran parte de las de carácter vanguardista. Conjuntamente, condenó la imagen de poesía universalista, nacionalista o subjetiva que podría desprenderse de tales manifestaciones.

Pero aquello no habría sido todo. Habría que añadir que las traducciones habrían implicado un quebranto de la visión contemporánea que los costarricenses tenemos de nuestra propia tradición lírica. Si bien es cierto durante buena parte del siglo pasado en Costa Rica se manejaba la hipótesis de que la poesía costarricense no seguía ninguna lógica discernible en cuanto a su desarrollo histórico-poético (Monge, 1991: 8 y 1992: 12), a partir de la década de 1970 esa imagen se ve sustituida por otra que muestra un ordenamiento evolutivo en esa actividad. Llegaron a distinguirse los periodos modernista y vanguardista de la poesía costarricense a los que ya me he referido, y dentro de ellos un relevo generacional de poetas que, partiendo de los modernistas, llega hasta nuestros días. Esa imagen de transformación poética histórica, constante y fluida a lo largo de un siglo y que se maneja a lo interno del foro poético-literario nacional, se ve truncada si se juzga a partir de las traducciones analizadas.

El efecto de las traducciones, o más bien de la imagen que proyectan, no necesariamente se habría limitado al ámbito literario, sino que también podría haber condicionado la imagen que se tendría de nuestra sociedad y que no necesariamente sería la que históricamente ciertos sectores de la misma se han esforzado por proyectar hacia el exterior. Al respecto cabe decir que las traducciones estudiadas, por ejemplo, parecen proyectar a la sociedad costarricense como más progresista de lo que a lo interno del país y en general se tendería a aceptar. La manera relativamente abierta e incluso un tanto revolucionaria y provocativa con que se trata en las traducciones asuntos de tipo sexual, sociopolítico y de género contrasta con aquella imagen 
comercializada de un país que se precia de ser pacifista, amigable, conservador de sus valores más tradicionales y tendente al diálogo como medio para resolver los problemas.

\section{Conclusiones: ¿Qué se puede decir sobre la traducción?}

¿Qué arroja este análisis sobre la traducción en general, y en particular sobre la traducción de literaturas periféricas como la nuestra? Al respecto, y con esto termino, tres breves apuntes nada más.

Lo primero es que la traducción de literaturas periféricas parece ser una actividad que se realiza con un muy alto grado de autonomía con respecto deldesarrollo poético-literario y sociohistórico de aquello que se traduce. Por lo tanto, los productos que resulten de la actividad no necesariamente serán representativos de las literaturas nacionales que se traduzcan. Tal fue el caso, como se ha presentado, del conjunto de traducciones de poesía costarricense que no fueron representativas, ni cualitativa ni cuantitativamente, de la tendencia modernista, posmodernista o prevanguardista de nuestra tradición lírica.

Segundo, dicha autonomía implica por extensión que ni los criterios que rigen la manera en que se debe traducir ni los que determinan aquello que debe traducirse, reflejan obligatoriamente los cambios en la realidad poético-literaria o sociohistórica del contexto literario de partida. Antes bien, reflejarían variaciones en los intereses de los ámbitos y agentes del contexto de recepción que se hacen cargo de tales procesos. En otras palabras, la selección de qué traducir y las formas que adoptan las traducciones una vez acabado el proceso de traducción, concordarían con una visión externa o preconcepción de lo que las literaturas periféricas (la costarricense, la centroamericana o latinoamericana en este caso) deberían ser según la visión que se tenga de ellas en los polos de recepción. La traducción no sería más que un instrumento utilizado para reforzar la imagen construida $a$ priori en el contexto de recepción de aquello que se traduce. Hasta aquí, ambos hechos refuerzan la primacía que diferentes escuelas 
modernas de traducción (polisistémicas y funcionalistas) han adscrito al polo de recepción sobre el de partida.

Tercero, esa misma no representatividad en la selección de la variedad de manifestaciones poético-literarias históricas del contexto de partida entra en conflicto directo con la imagen tradicional que tenemos de la traducción como un medio de difusión democrático o puente neutral entre culturas. Es fundamental que dejemos de entender a la traducción con ojos idealistas, y comencemos a percibirla como aquello que a todas luces parece ser: una actividad altamente condicionada, parcializada, adecuada y selectiva, tanto en sus procesos como en sus resultados. 